Article

\title{
Effect of Dilute Acid and Alkali Pretreatments on the Catalytic Performance of Bamboo-Derived Carbonaceous Magnetic Solid Acid
}

\author{
Yikui Zhu ${ }^{1,2}$, Jiawei Huang ${ }^{1,2}$, Shaolong Sun ${ }^{3}$, Aimin $\mathrm{Wu}^{1,2, *}$ and Huiling $\mathrm{Li}^{1,2, *}$ \\ 1 State Key Laboratory for Conservation and Utilization of Subtropical Agro-bioresources, South China \\ Agricultural University, Guangzhou 510642, China; ZhuYKWerid@163.com (Y.Z.); \\ jiaweihuangkawy@gmail.com (J.H.) \\ 2 Guangdong Key Laboratory for Innovative Development and Utilization of Forest Plant Germplasm, \\ South China Agricultural University, Guangzhou 510642, China \\ 3 College of Natural Resources and Environment, South China Agricultural University, Guangzhou 510642, \\ China; sunshaolong328@scau.edu.cn \\ * Correspondence: wuaimin@scau.edu.cn (A.W.); lihl@scau.edu.cn (H.L.); Tel.: +020-85280259 (A.W.)
}

Received: 26 January 2019; Accepted: 1 March 2019; Published: 7 March 2019

\begin{abstract}
Lignocellulose is a widely used renewable energy source on the Earth that is rich in carbon skeletons. The catalytic hydrolysis of lignocellulose over magnetic solid acid is an efficient pathway for the conversion of biomass into fuels and chemicals. In this study, a bamboo-derived carbonaceous magnetic solid acid catalyst was synthesized by $\mathrm{FeCl}_{3}$ impregnation, followed by carbonization and $-\mathrm{SO}_{3} \mathrm{H}$ group functionalization. The prepared catalyst was further subjected as the solid acid catalyst for the catalytic conversion of corncob polysaccharides into reducing sugars. The results showed that the as-prepared magnetic solid acid contained $-\mathrm{SO}_{3} \mathrm{H},-\mathrm{COOH}$, and polycyclic aromatic, and presented good catalytic performance for the hydrolysis of corncob in the aqueous phase. The concentration of $\mathrm{H}^{+}$was in the range of 0.6487 to $2.3204 \mathrm{mmol} / \mathrm{g}$. Dilute acid and alkali pretreatments of raw material can greatly improve the catalytic activity of bamboo-derived carbonaceous magnetic solid acid. Using the catalyst prepared by $0.25 \% \mathrm{H}_{2} \mathrm{SO}_{4}$-pretreated bamboo, $6417.5 \mathrm{mg} / \mathrm{L}$ of reducing sugars corresponding to $37.17 \%$ carbohydrates conversion could be obtained under the reaction conditions of $120^{\circ} \mathrm{C}$ for $30 \mathrm{~min}$.
\end{abstract}

Keywords: bamboo; pretreatment; magnetic solid acid; corncob; reducing sugar

\section{Introduction}

The depletion of fossil fuel reserves and climate change issues have raised concerns about renewable petroleum alternatives with the increment of global energy demand [1,2]. Biomass has received increasing attention in recent decades due to it being widespread, abundant, diverse, and inexpensive. Moreover, it has been intensively investigated as a highly sustainable carbon-containing source for the production of bioplatform molecules and biochemicals. The unique property of lignocellulosic biomass as the only renewable carbon carrier makes it an attractive source for bioenergy production. The conversion of lignocellulosic biomass to useful chemicals and biofuels via green and efficient approaches is one of the most popular topics in recent years [3]. However, problems such as its high pretreatment cost and difficulty in catalyst recovery hinder their utilization. Therefore, the development of new reaction techniques, including novel catalysts, novel pretreatment methods, or reaction media, is crucial for biomass-to-bioenergy industries [4].

The cell wall of lignocellulose mainly consists of lignin, cellulose, and hemicellulose [5]. The amount of each constituent is related to the type of plant species and their age [6]. Although 
lignocellulose is rich in cellulose and hemicellulose, its high lignin content, and tough and strong physical structure make it difficult to convert into chemicals and biofuels. Chemical methods such as acid pretreatment are commonly used to prepare reducing sugars. Compared to concentrated acid pretreatment, dilute acid pretreatment needs a higher reaction temperature and longer reaction time. Although the required reaction time and temperature of concentrated acid pretreatment are milder than that of dilute acid pretreatment, disadvantages such as a high equipment loss rate and environmental pollution impede its competitiveness [7]. In order to achieve low-cost and green sustainable production, solid acid catalysts had been proposed and applied to the production of reducing sugars [8].

The most common used solid acid catalysts include silica solid acids [9], biopolymer-based solid acids [10], ion-exchange resin solid acids [11], zirconia solid acids [12], and hydroxyapatite solid acids [13]. Nowadays, green catalysts, which are based on the use of renewable raw materials, are getting more and more attention [14]. Hence, more environmentally and economically-friendly solid acids were proposed. Biomass-based magnetic solid acid is prepared by using lignocellulose as a carbon carrier. It was regarded as a porous solid with a large surface area. Biomass-based magnetic solid acid was widely used in a large amount of reactions, such as the separation and purification of gases, and the removal of organic pollutants from water, refrigeration, and electrochemical devices [15]. Compared to traditional heterogeneous acid catalysts, the biomass-based magnetic solid acid has the characteristics of simple preparation, better recovery, convenient material selection, and low cost. Li et al. used a corn straw biomass-based solid acid to catalyze the hydrolysis of corn straw. The results showed that the prepared catalyst exhibited high catalytic activity for the conversion of corn straw into levulinic acid, and the most favorable values of catalyst dosage, hydrolysis temperature, hydrolyzation duration, and the maximum yield of LA were $3 \mathrm{~g}, 249.66^{\circ} \mathrm{C}, 67.3 \mathrm{~min}$, and $23.17 \%$, respectively [15]. Chen et al. prepared a series of carbonaceous solid acids from biorenewable feedstock and used them as catalysts for the direct conversion of carbohydrates into 5-ethoxymethylfurfural (EMF) [16]. The results showed that the prepared catalysts presented a porous structure, high acid density, and easy separation. An EMF yield of $63.2 \%$ could be obtained from fructose at $120^{\circ} \mathrm{C}$. Lignocellulose contains a large amount of hemicellulose. It has been reported that the yield of xylan-based activated carbon (mainly based on hemicellulose) was much lower than that of cellulose and lignin due to the instability of hemicellulose [17]. Moreover, the presence of hemicellulose decreases the specific surface area of the solid acid when the carbonized temperature was up to $400{ }^{\circ} \mathrm{C}$, which may reduce the catalytic performance of the solid acid. Simultaneously, hemicelluloses decompose at low temperatures and produce waste gas, which lead to environmental pollution. Therefore, in order to achieve a better carbon precursor, the biomass needs to be treated with suitable pretreatment methods [18]. Dilute acid and dilute alkali pretreatments are usually employed to destroy the complex structure of biomass. Dilute acid pretreatment can not only effectively remove hemicellulose, but can also minimize the damage of lignin and cellulose [19]. Meanwhile, dilute alkali pretreatment can effectively expand the biomass, leaving carbohydrates (cellulose and hemicelluloses) behind, thus increasing the contact area of the solid acid [20].

Bamboo is a fast-growing perennial herbaceous plant with a large phytomass, which is widely distributed in China [21]. Bamboo has many excellent properties that make it a suitable carbonized material for catalyst preparation, such as its porous structure and high thermal stability. Corncob is one of the abundant lignocellulose sources in China, and the annual global corncob production exceeds 1.03 billion metric tons, which can be used as a substrate for the production of platform products [8]. In this study, a bamboo-derived carbonaceous magnetic solid acid with a unique magnetic core-shell and high acid content was prepared by the impregnation-incomplete carbonization-sulfonation method and used as a magnetic solid acid to catalyze the hydrolysis of corncob to produce reducing sugar. The effects of dilute acid and dilute alkaline pretreatments on the catalytic performance of the as-prepared catalysts were investigated. The pretreated bamboo-derived carbonaceous support is expected with a porous structure for the introducing of $-\mathrm{SO}_{3} \mathrm{H}$, forming layers of adsorbate molecules that can interact with reactants. This process mainly comprises two steps: the preparation 
of bamboo-based magnetic solid acid and the catalytic hydrolysis of corncob by solid acid to prepare reducing sugars.

\section{Results and Discussion}

\subsection{Characterization of the Catalyst}

The Fourier transform infrared (FT-IR) spectrum of bamboo-derived carbonaceous magnetic solid acid prepared by different pretreatment methods is shown in Figure 1 . The peak of $1560 \mathrm{~cm}^{-1}$ that appeared in all the samples corresponds to the $\mathrm{C}=\mathrm{C}$ stretching vibration in aromatic carbons [22]. The typical band that appeared at $585 \mathrm{~cm}^{-1}$ represents the $\mathrm{Fe}-\mathrm{O}$ vibration in $\mathrm{Fe}_{3} \mathrm{O}_{4}$, indicating that the solid acid was successfully magnetized during magnetization [23]. Moreover, strong bands such as $1041 \mathrm{~cm}^{-1}$ and $1380 \mathrm{~cm}^{-1}\left(\mathrm{O}=\mathrm{S}=\mathrm{O}\right.$ asymmetric) indicate that the $-\mathrm{SO}_{3} \mathrm{H}$ group was successfully introduced into the bamboo-derived magnetic solid materials [24]. However, the strength of $1137 \mathrm{~cm}^{-1}$ $(\mathrm{O}=\mathrm{S}=\mathrm{O}$ symmetric stretching vibrations) was varied between solid acids prepared by different pretreatment methods. The order of the strength of the $\mathrm{O}=\mathrm{S}=\mathrm{O}$ peak at $1137 \mathrm{~cm}^{-1}$ was: dilute acid pretreated $>$ dilute alkali pretreated $>$ deionized (DI) water pretreated. The activated carbon prepared by dilute acid pretreatment was better combined with sulfuric acid, which was consistent with the subsequent catalytic hydrolysis results. In addition, a band at $3423 \mathrm{~cm}^{-1}$ corresponds to the $\mathrm{O}-\mathrm{H}$ stretching vibration in $-\mathrm{COOH}$, suggesting that phenolic $-\mathrm{OH}$ groups were also successfully generated to the prepared solid acid during the carbonization and sulfonation processes [25].

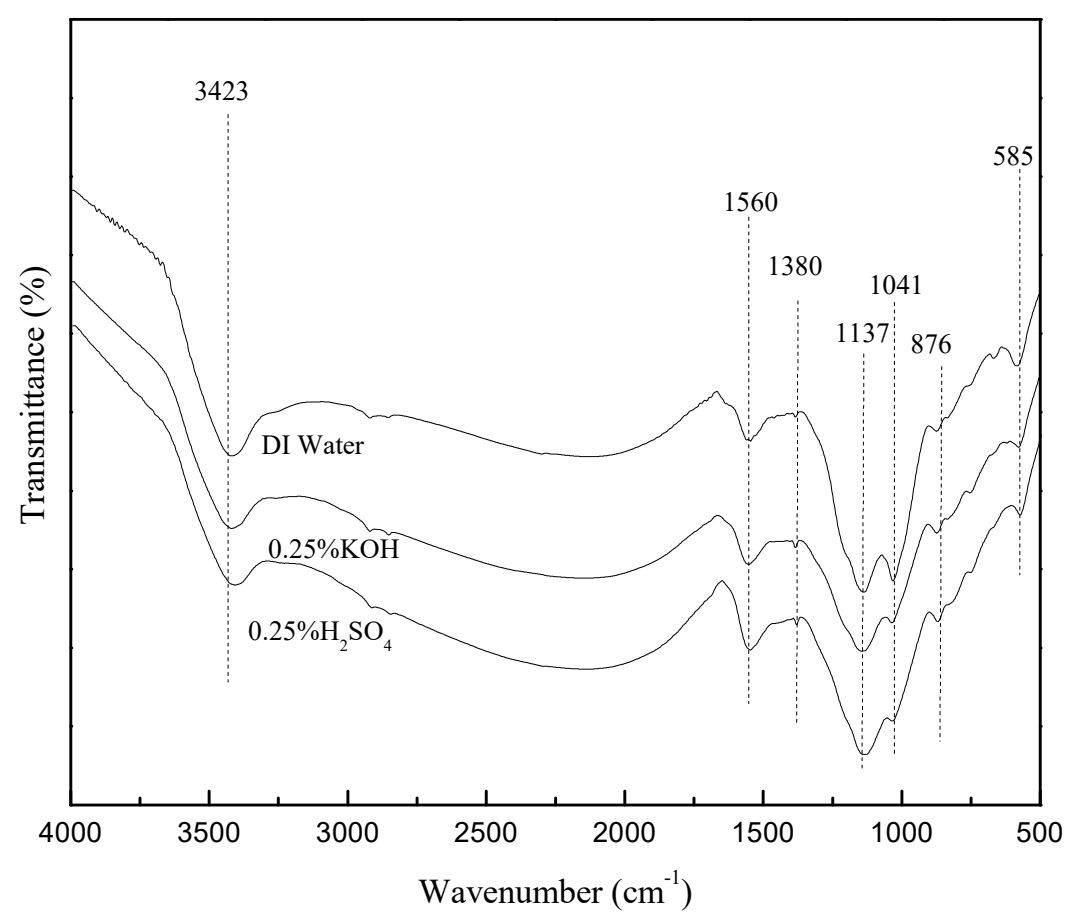

Figure 1. Fourier transform infrared (FT-IR) spectrum of bamboo-derived carbonaceous magnetic solid acid.

In order to understand the $\mathrm{H}^{+}$concentration on the surface of the prepared materials, an acid/base titration test was performed, and the results are shown in Figure 2. $\mathrm{H}^{+}$concentration on the surface of bamboo-derived carbonaceous magnetic solid acid prepared by different pretreatment methods was in the range of $0.6487 \mathrm{mmol} / \mathrm{g}$ to $2.3204 \mathrm{mmol} / \mathrm{g}$. The acidity of the catalyst increased with the increment of acid/alkaline concentration, which may be related to the better interaction between the substrate and chemicals [18]. Compared with dilute alkali pretreatment, the acid density of the solid acids prepared by dilute acid pretreatment is higher, except at high concentration ( $2 \%)$. This phenomenon 
was consistent with the above FT-IR results. However, the acid density of the sample prepared by $2 \%$ $\mathrm{KOH}$ was much higher than that of the sample prepared by $2 \% \mathrm{H}_{2} \mathrm{SO}_{4}$. Furthermore, $2.3204 \mathrm{mmol} / \mathrm{g}$ of $\mathrm{H}^{+}$concentration could be obtained from the DI-pretreated samples. These results indicated that the surface of a bamboo-derived carbonaceous magnetic solid had been successfully acidified.
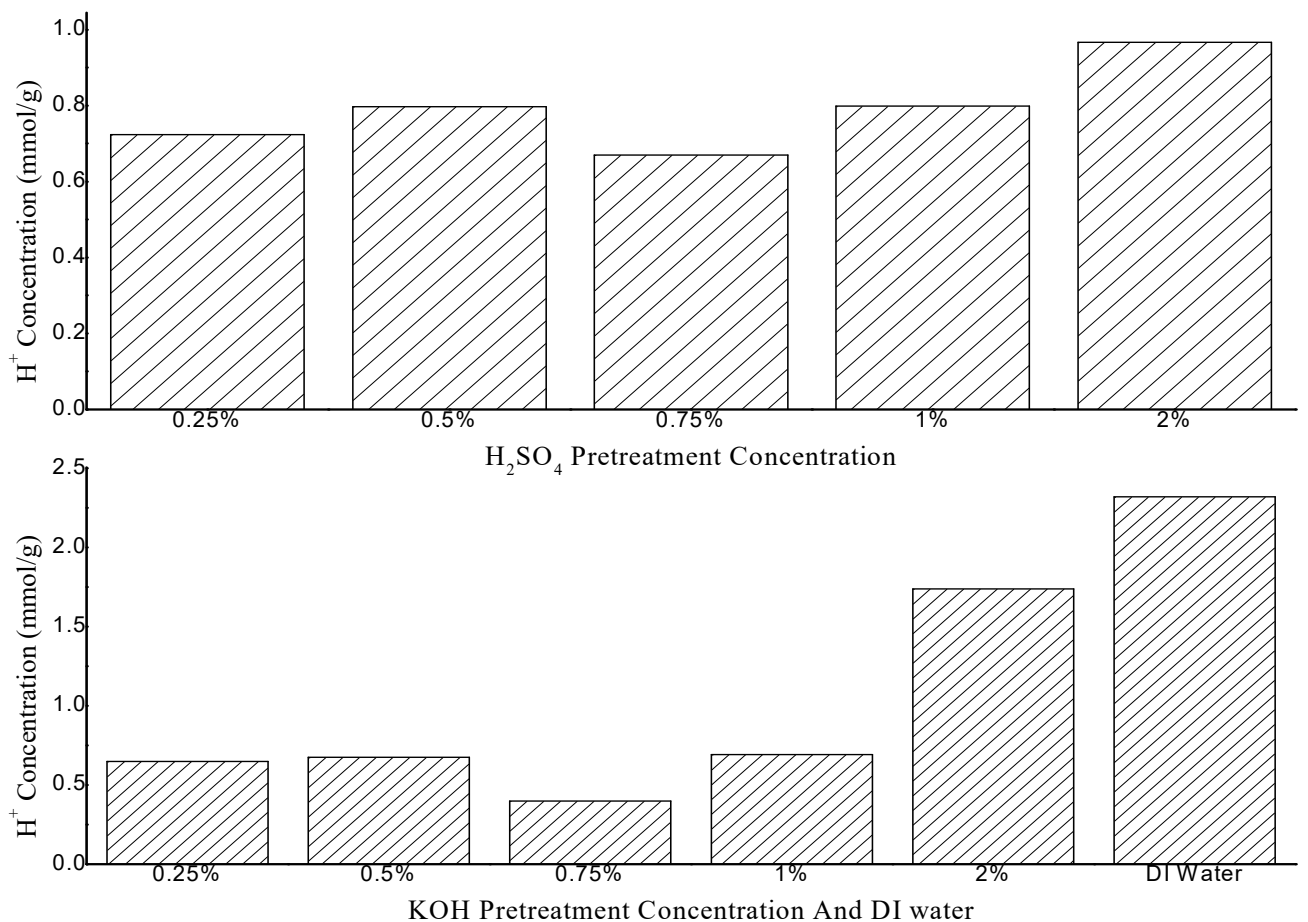

Figure 2. $\mathrm{H}^{+}$concentration of the bamboo-derived magnetic solid acid prepared by different pretreatment conditions.

During the carbonization and sulfonation processes, changes occurred in the crystallinity of the material. The XRD spectras of bamboo-derived magnetic solid acid prepared at different pretreatment conditions are shown in Figure 3. The observed sharp peaks at $2 \theta$ values of $35.61^{\circ}, 57^{\circ}$, and $62^{\circ}$ were assigned to the (220), (311), and (440) lattice planes of $\mathrm{Fe}_{3} \mathrm{O}_{4}$ (JCPDS19-629) [22,24], which indicated that the carbon coated by $\mathrm{Fe}_{3} \mathrm{O}_{4}$ existed in the form of polycyclic aromatic hydrocarbons, and their structures were kept stable during the sulfonation process. Moreover, material prepared by $0.5 \%$ $\mathrm{H}_{2} \mathrm{SO}_{4}$ pretreated bamboo showed the strongest intensity at $35.61^{\circ}$, which may lead to the better catalytic performance for the reducing production of sugars. This speculation was also verified by the following catalysis experiments. Compared with the solid acid prepared by dilute alkali pretreated under the same concentration, the peak intensity of the dilute acid pretreated sample was higher, which was consistent with the results of the subsequent catalytic output. In addition, both patterns exhibited a broad and weak diffraction peak at $2 \theta=20-30^{\circ}$, which was due to the presence of amorphous carbon, which was composed of aromatic carbon sheets oriented in a random fashion [26]. 


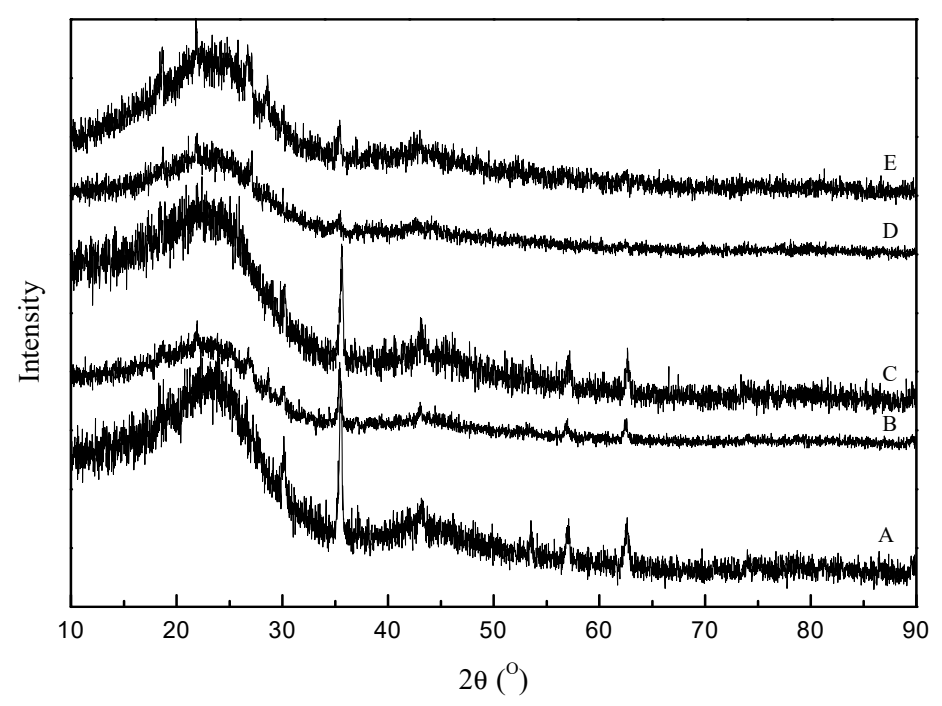

Figure 3. XRD spectra of bamboo-derived carbonaceous magnetic solid acid prepared with different pretreatment conditions (A: $0.5 \% \mathrm{H}_{2} \mathrm{SO}_{4}$ pretreated sample; $\mathrm{B}: 2 \% \mathrm{H}_{2} \mathrm{SO}_{4}$ pretreated sample; $\mathrm{C}: 0.5 \%$ $\mathrm{KOH}$ pretreated sample; D: $2 \% \mathrm{KOH}$ pretreated sample; E: Deionized (DI) water pretreated sample).

The thermal behavior of the bamboo-derived magnetic solid acid (pretreated by $0.25 \% \mathrm{H}_{2} \mathrm{SO}_{4}$ ) was shown in Figure 4. The thermal decomposition of the prepared catalyst can be divided into three stages. The weight loss which occurred before $150{ }^{\circ} \mathrm{C}$ was mainly because of the evaporation of water adsorbed on the surface of the material [27]. The weight loss stage from $180^{\circ} \mathrm{C}$ to $420^{\circ} \mathrm{C}$ corresponded to the decomposition of $-\mathrm{SO}_{3} \mathrm{H}$ groups [3]. The last stage that occurred above $400{ }^{\circ} \mathrm{C}$ was attributed to the further condensation of amorphous carbons [25]. About an $11 \%$ weight loss of the Fe precursor may be occurred between $180-500{ }^{\circ} \mathrm{C}$, which may be ascribed to the decomposition and conversion reaction of the Fe species of the catalyst at high temperatures [24].

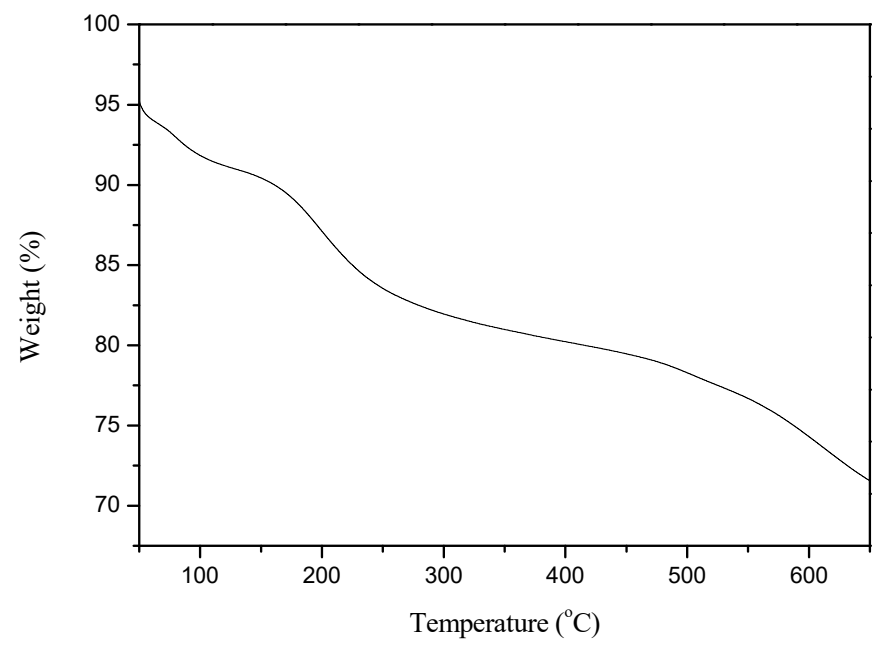

Figure 4. Thermal behavior of the bamboo-derived magnetic solid acid (pretreated by $0.25 \% \mathrm{H}_{2} \mathrm{SO}_{4}$ ).

\subsection{Effects of Pretreatment Conditions on the Chemical Composition of Bamboo}

The detection of chemical composition of lignocelluloses can visually verify their structure in different conditions. In order to evaluate the effects of dilute acid and alkali pretreatments on the major sugar compositions of bamboo, dewaxed bamboo was treated by dilute $\mathrm{H}_{2} \mathrm{SO}_{4}$ and $\mathrm{KOH}$ in various concentrations $\left(0.25 \%, 0.5 \%, 0.75 \%, 1 \%\right.$, and $2 \%$ ) in a solid ratio of $1: 10(\mathrm{~g} / \mathrm{mL})$ at $120{ }^{\circ} \mathrm{C}$ for $30 \mathrm{~min}$, respectively. The major sugar components of hydrolysates and solid residues are shown in Tables 1 and 2. 
Table 1. Concentrations of major sugars in bamboo hydrolysates (mg/L).

\begin{tabular}{ccccc}
\hline Entry & Sample & Xylose & Arabinose & Glucose \\
\hline 1 & $0.25 \% \mathrm{H}_{2} \mathrm{SO}_{4}$ & 1995.35 & 510.50 & 166.85 \\
2 & $0.5 \% \mathrm{H}_{2} \mathrm{SO}_{4}$ & 2157.45 & 582.70 & 243.45 \\
3 & $0.75 \% \mathrm{H}_{2} \mathrm{SO}_{4}$ & 2805.00 & 605.05 & 266.75 \\
4 & $1 \% \mathrm{H}_{2} \mathrm{SO}_{4}$ & 6278.50 & 665.25 & 417.15 \\
5 & $2 \% \mathrm{H}_{2} \mathrm{SO}_{4}$ & 8258.90 & 711.00 & 613.30 \\
6 & $0.25 \% \mathrm{KOH}$ & $\mathrm{ND}^{\mathrm{a}}$ & $\mathrm{ND}$ & $\mathrm{ND}$ \\
7 & $0.5 \% \mathrm{KOH}$ & $\mathrm{ND}$ & $\mathrm{ND}$ & $\mathrm{ND}$ \\
8 & $0.75 \% \mathrm{KOH}$ & $\mathrm{ND}$ & $\mathrm{ND}$ & $\mathrm{ND}$ \\
9 & $1 \% \mathrm{KOH}$ & $\mathrm{ND}$ & $\mathrm{ND}$ & $\mathrm{ND}$ \\
10 & $2 \% \mathrm{KOH}$ & $\mathrm{ND}$ & $\mathrm{ND}$ & $\mathrm{ND}$ \\
11 & $\mathrm{DI} \mathrm{Water}$ & $\mathrm{ND}$ & $\mathrm{ND}$ & $\mathrm{ND}$ \\
\hline
\end{tabular}

${ }^{\mathrm{a}} \mathrm{ND}$ : Undetectable.

Table 2. Major sugar composition of bamboo residues (g/g).

\begin{tabular}{ccccc}
\hline Entry & Sample & Xylose & Arabinose & Glucose \\
\hline 1 & $0.25 \% \mathrm{H}_{2} \mathrm{SO}_{4}$ & 9.61 & 0.058 & 38.02 \\
2 & $0.5 \% \mathrm{H}_{2} \mathrm{SO}_{4}$ & 6.08 & 0.051 & 39.93 \\
3 & $0.75 \% \mathrm{H}_{2} \mathrm{SO}_{4}$ & 5.71 & $\mathrm{ND}^{\mathrm{a}}$ & 42.05 \\
4 & $1 \% \mathrm{H}_{2} \mathrm{SO}_{4}$ & 4.17 & $\mathrm{ND}$ & 44.81 \\
5 & $2 \% \mathrm{H}_{2} \mathrm{SO}_{4}$ & 4.83 & $\mathrm{ND}$ & 48.31 \\
6 & $0.25 \% \mathrm{KOH}$ & 9.69 & 0.69 & 40.61 \\
7 & $0.5 \% \mathrm{KOH}$ & 12.14 & 0.84 & 40.55 \\
8 & $0.75 \% \mathrm{KOH}$ & 11.79 & 0.88 & 43.14 \\
9 & $1 \% \mathrm{KOH}$ & 14.74 & 1.15 & 50.23 \\
10 & $2 \% \mathrm{KOH}$ & 12.05 & 0.74 & 51.82 \\
11 & $\mathrm{DI} \mathrm{Water}$ & 10.93 & 0.74 & 33.94 \\
\hline
\end{tabular}

${ }^{\mathrm{a}} \mathrm{ND}$ : Undetectable.

In the absence of a catalyst $\left(\mathrm{H}_{2} \mathrm{SO}_{4}\right.$ and $\left.\mathrm{KOH}\right)$, the dissolution of reducing sugars (xylose, arabinose, and glucose) was not observed under the investigated conditions (Table 1, entry 11). However, after dilute $\mathrm{H}_{2} \mathrm{SO}_{4}$ was added as the catalyst, the contents of reducing sugars in the hydrolysates enhanced sharply (Table 1, entries 1-5). The productions of xylose, arabinose, and glucose increased from $1995.35 \mathrm{mg} / \mathrm{L}$ to $8258.9 \mathrm{mg} / \mathrm{L}, 510.5 \mathrm{mg} / \mathrm{L}$ to $711.0 \mathrm{mg} / \mathrm{L}$, and $166.85 \mathrm{mg} / \mathrm{L}$ to $613.3 \mathrm{mg} / \mathrm{L}$ with the acid concentration increased from $0.25 \%$ to $2.0 \%$, respectively. This result indicated that about $74.74 \%$ of hemicellulose and $1.56 \%$ of cellulose could be extracted by $2.0 \% \mathrm{H}_{2} \mathrm{SO}_{4}$ at $120{ }^{\circ} \mathrm{C}$ for $30 \mathrm{~min}$. Therefore, the major compounds in the acid-treated bamboo residues may be cellulose and lignin. This phenomenon illustrated that a higher acid concentration benefited the dissolution of bamboo hemicellulose, especially for xylose during the pretreatment process. In addition, the hemicellulose structure of bamboo was elucidated as arabinoxylan oligosaccharides with xylose as the backbone and arabinose as the side chain [27]. Compared with xylose (16.61-68.83\%), about $25.52-35.55 \%$ of arabinose was removed during dilute $\mathrm{H}_{2} \mathrm{SO}_{4}$ pretreatment, which suggested that the main chain of bamboo hemicellulose breaks faster than the side chain. However, glucose, xylose, and arabinose could not be detected in the $\mathrm{KOH}$-pretreated hydrolysates (Table 1, entries 6-10), which suggested that dilute alkali pretreatment showed less power for the dissolution of hemicellulose and cellulose from bamboo than dilute acid pretreatment, which was consistent with the previous reports [2]. As shown in Table 1, xylose was the dominating sugar in the liquid fractions, and its content increased gradually as the pretreatment acid concentration increased. Moreover, it was found that arabinose was the secondary sugar constituent in the liquid fractions, and the yield of glucose was much lower than that of the former two. These results indicated that the dilute acid pretreatment mainly promotes the dissolution of hemicellulose rather than cellulose. 
The hydrolyzed residues were simultaneously subjected to sugar analysis to verify the effect of pretreatments on the change of bamboo composition (Table 2). The contents of xylose and arabinose decreased gradually as the concentration of dilute acid increased (Table 2, entries 1-5), which was consistent with the results in Table 1. Moreover, a sugar composition analysis of dilute alkali-pretreated bamboo showed that the contents of major monosaccharides were kept stable in different $\mathrm{KOH}$ concentrations. This phenomenon suggested that cellulose and hemicellulose did not change much after the dilute alkali pretreatment. No monosaccharides could be detected in the hydrolysates after the dilute alkali and DI water pretreatments, which may be due to their further conversion into formic acid, acetic acid, furfural, etc. [17].

An FT-IR spectra of the bamboo residues obtained from dilute acid and dilute alkali pretreatments was performed to complete the study of all the samples from the experimental design (Figure 5). A band near $1733 \mathrm{~cm}^{-1}$ was ascribed to the stretching of $\mathrm{C}=\mathrm{O}$ in hemicelluloses [28]. However, the absorption of this band decreased with the increment of sulfuric acid concentration, which suggested that the hemicellulose partly dissolved during the pretreatment process. Additionally, strong bonds at $1205 \mathrm{~cm}^{-1}$ (OH in-plane bending in cellulose I and cellulose II), $1160 \mathrm{~cm}^{-1}$ (C-O-C stretching asymmetric), $1100 \mathrm{~cm}^{-1}$ (glucose ring-stretching asymmetric), $898 \mathrm{~cm}^{-1}$ ( $\beta$-glycosidic linkages between glucose unites in cellulose) could be observed both in dilute acid and alkali pretreated samples [27]. The strong bands at $1596 \mathrm{~cm}^{-1}$ and $1267 \mathrm{~cm}^{-1}$ corresponded to the aromatic skeletal vibration breathing with $\mathrm{C}=\mathrm{O}$ stretching and vibration of the guaiacyl ring of lignin, respectively [16], which suggested that hemicelluloses could be removed effectively during the pretreatment process, resulting in the increment of the relative content of lignin in the bamboo residues. Therefore, the FT-IR results showed that the relative amount of the lignin and cellulose increased during the dilute acid/alkaline pretreatment process, and the change of the chemical composition of bamboo may affect the catalytic ability of the following prepared bamboo-derived carbonaceous magnetic solid acid.

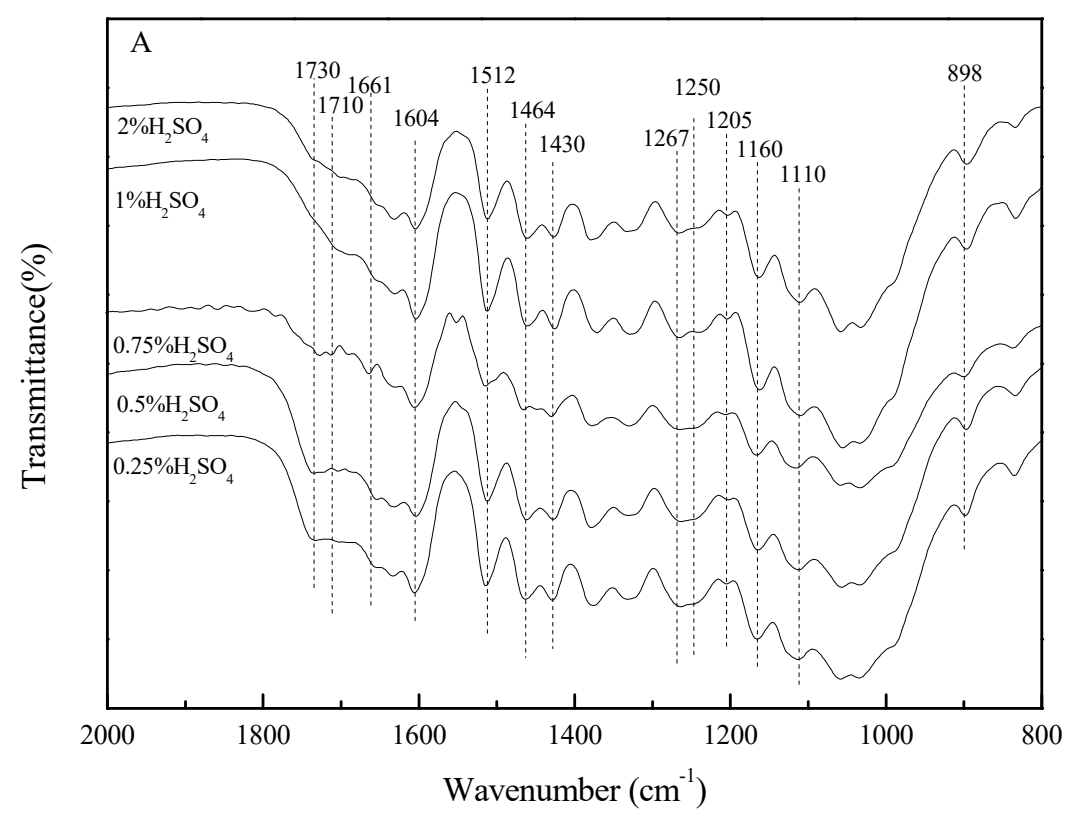

Figure 5. Cont. 


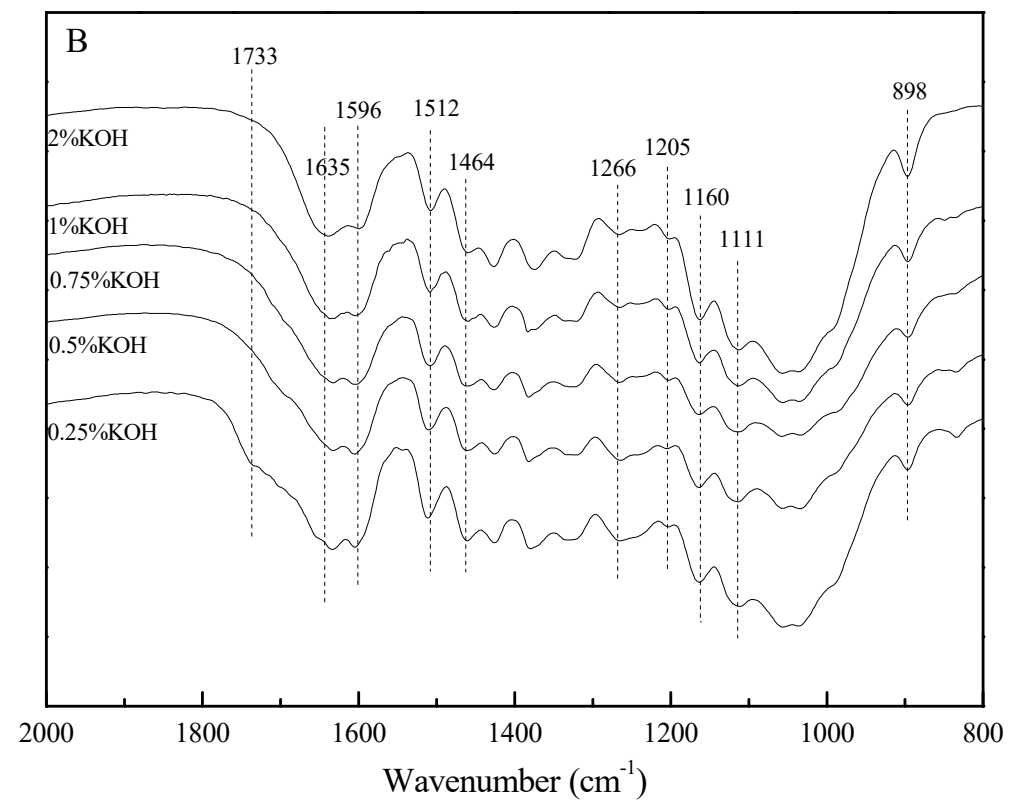

Figure 5. FT-IR spectra of dilute acid and alkali pretreated bamboo ((A) spectra of dilute acid pretreated bamboo; (B) spectra of dilute alkali pretreated bamboo).

\subsection{Hydrolysis of Corncob with Bamboo-Derived Carbonaceous Magnetic Solid Acid}

It should be noted that the pretreatment conditions had a great influence on the catalytic performance of the prepared bamboo-derived carbonaceous magnetic solid acid. In this study, experiments were executed for the catalytic hydrolysis of corncob at $120^{\circ} \mathrm{C}$ for $30 \mathrm{~min}$ via the prepared magnetic solid acids. The main components of the hydrolysates and corncob solid residues were shown in Tables 3 and 4 . The basic trend of xylose, arabinose, and glucose yields decreased when the pretreatment concentration of $\mathrm{H}_{2} \mathrm{SO}_{4}$ rose from $0.25 \%$ to $2 \%$, which may be due to the reduction of the carbohydrates contents in the $\mathrm{H}_{2} \mathrm{SO}_{4}$-pretreated bamboo residues [29]. A higher carbohydrate content can achieve higher surface areas of specific materials during carbonization, which may be because an incomplete carbonization process is primarily the process of carbohydrates dehydrating and becoming volatile [18]. Moreover, the acidity of solid acids enhanced when prepared by a higher $\mathrm{H}_{2} \mathrm{SO}_{4}$ concentration. During the hydrolysis process, the obtained reducing sugar will be further catalyzed to form other products, such as furfural, 5-hydroxymethylfurfural, and so on [30]. However, the opposite phenomenon was observed for bamboo-derived magnetic solid acid prepared by dilute alkali pretreatment. When the $\mathrm{KOH}$ concentration was raised from $0.25 \%$ to $2 \%$, the yields of xylose, arabinose, and glucose increased from $1856.2 \mathrm{mg} / \mathrm{L}$ to $2601.0 \mathrm{mg} / \mathrm{L}, 27.4 \mathrm{mg} / \mathrm{L}$ to $402.7 \mathrm{mg} / \mathrm{L}$, and $672.5 \mathrm{mg} / \mathrm{L}$ to $1226.2 \mathrm{mg} / \mathrm{L}$, respectively. This phenomenon may be because lignin was partly removed during the dilute alkali pretreatment, leaving most of the carbohydrates behind [31]. Therefore, higher reducing sugars yields could be obtained from the solid acid prepared by high concentration alkali-pretreated bamboo. In addition, solid acid prepared by authohydrolysis presented the lowest reducing sugars productivity, which may be ascribed to the weak damage strength of the bamboo structure under mild conditions. The highest reducing sugars yield of $37.17 \%$ could be obtained from bamboo-derived carbonaceous magnetic solid acid prepared by $0.25 \% \mathrm{H}_{2} \mathrm{SO}_{4}$-pretreated bamboo. The prepared catalyst possessed a good catalytic performance for the conversion of hemicellulose into xylose and arabinose without further dehydration to form other products, which may be due to its moderate acidity and crystallinity. 
Table 3. Effect of the pretreatment conditions on the catalytic performance of bamboo-derived magnetic solid acid (mg/L).

\begin{tabular}{ccccc}
\hline Entry & Sample & Xylose & Arabinose & Glucose \\
\hline 1 & $0.25 \% \mathrm{H}_{2} \mathrm{SO}_{4}$ & 4643.40 & 662.80 & 1111.30 \\
2 & $0.5 \% \mathrm{H}_{2} \mathrm{SO}_{4}$ & 3100.05 & 492.15 & 1100.90 \\
3 & $0.75 \% \mathrm{H}_{2} \mathrm{SO}_{4}$ & 2284.05 & 360.20 & 683.6 \\
4 & $1 \% \mathrm{H}_{2} \mathrm{SO}_{4}$ & 3356.75 & 497.80 & 991.40 \\
5 & $2 \% \mathrm{H}_{2} \mathrm{SO}_{4}$ & 2259.40 & 318.40 & 219.50 \\
6 & $0.25 \% \mathrm{KOH}$ & 1856.20 & 278.40 & 672.50 \\
7 & $0.5 \% \mathrm{KOH}$ & 2642.85 & 366.55 & 668.50 \\
8 & $0.75 \% \mathrm{KOH}$ & 2358.30 & 320.90 & 562.90 \\
9 & $1 \% \mathrm{KOH}$ & 2034.75 & 302.4 & 850.80 \\
10 & $2 \% \mathrm{KOH}$ & 2601.00 & 402.70 & 1226.20 \\
11 & $\mathrm{DI} \mathrm{Water}$ & 286.90 & 25.55 & 386.45 \\
\hline
\end{tabular}

Reaction conditions: $1 \mathrm{~g}$ of corncob, $0.2 \mathrm{~g}$ of bamboo-derived magnetic solid acid, $20.0 \mathrm{~mL}$ of DI water, $300 \mathrm{rpm}$, $120{ }^{\circ} \mathrm{C}$ and $30 \mathrm{~min}$.

Table 4. Analysis of corncob solid residue after catalysis (mg/L).

\begin{tabular}{ccccc}
\hline Entry & Sample & Xylose & Arabinose & Glucose \\
\hline 1 & $0.25 \% \mathrm{H}_{2} \mathrm{SO}_{4}$ & 22.35 & 0.00 & 1172.05 \\
2 & $0.5 \% \mathrm{H}_{2} \mathrm{SO}_{4}$ & 46.30 & 0.00 & 1288.85 \\
3 & $0.75 \% \mathrm{H}_{2} \mathrm{SO}_{4}$ & 205.85 & 0.10 & 874.35 \\
4 & $1 \% \mathrm{H}_{2} \mathrm{SO}_{4}$ & 39.20 & 0.00 & 1150.00 \\
5 & $2 \% \mathrm{H}_{2} \mathrm{SO}_{4}$ & 63.55 & 0.00 & 1193.85 \\
6 & $0.25 \% \mathrm{KOH}$ & 42.00 & 0.00 & 1038.50 \\
7 & $0.5 \% \mathrm{KOH}$ & 44.30 & 0.00 & 1073.10 \\
8 & $0.75 \% \mathrm{KOH}$ & 105.30 & 0.65 & 959.90 \\
9 & $1 \% \mathrm{KOH}$ & 197.15 & 0.50 & 817.05 \\
10 & $2 \% \mathrm{KOH}$ & 0.00 & 0.00 & 1004.10 \\
11 & $\mathrm{DI} \mathrm{Water}$ & 0.00 & 0.00 & 999.05 \\
\hline
\end{tabular}

Determining the recyclability of a catalyst is important to evaluate its efficiency based on economic and environmental factors. The solid acids prepared in this study had the characteristic of being easily separated due to their magnetic properties. In this study, the recyclability of the prepared bamboo-derived magnetic solid acid (pretreated by $0.25 \% \mathrm{H}_{2} \mathrm{SO}_{4}$ ) was performed, and the results are shown in Figure 6. After three recycle runs, the prepared catalyst remained active for the conversion of corncob into reducing sugar. In comparison to the fresh catalyst, the yields of xylose, arabinose, and glucose decreased slightly from $4643.4 \mathrm{mg} / \mathrm{L}$ to $3902.5 \mathrm{mg} / \mathrm{L}, 662.8 \mathrm{mg} / \mathrm{L}$ to $455.5 \mathrm{mg} / \mathrm{L}$, and $1111.3 \mathrm{mg} / \mathrm{L}$ to $805.4 \mathrm{mg} / \mathrm{L}$ after three recycles, respectively, which suggested that the prepared catalyst had good reusability. Compared with conventional solid acids, the biomass-based magnetic solid acid used in this study has the advantages of easy recycling, moderate acidity, and widely resourced. Moreover, it possessed good catalytic performance for the conversion of lignocellulosic raw materials into reducing sugars. 


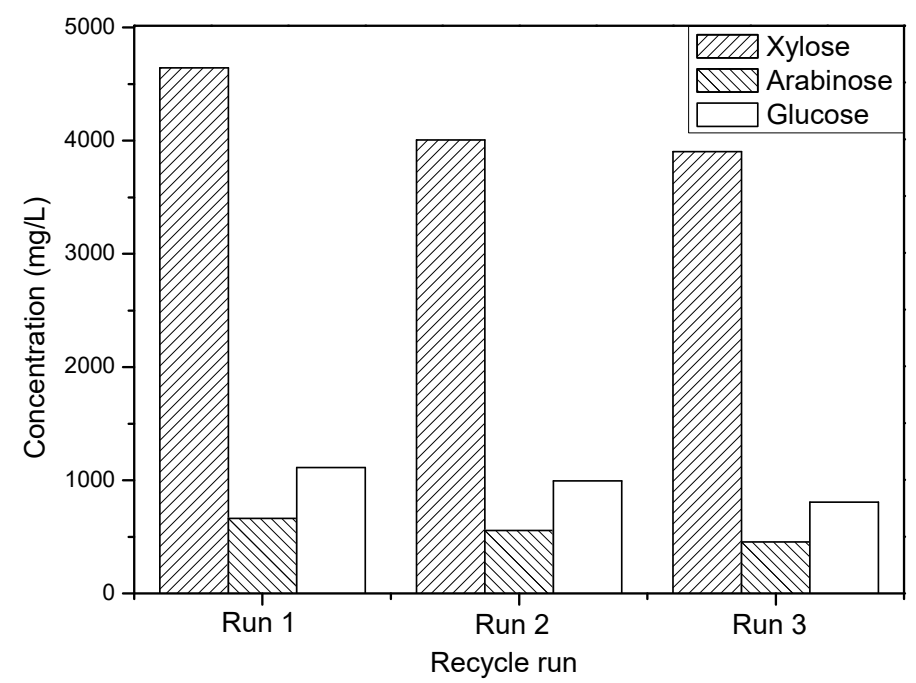

Figure 6. Recyclability of the bamboo-derived magnetic solid acid (pretreated by $0.25 \% \mathrm{H}_{2} \mathrm{SO}_{4}$ ).

\section{Materials and Methods}

\subsection{Materials}

The bamboo used in the experiment was collected from Hunan Province, China. Prior to the experiments, the bamboo was decorticated, ground, and sieved to about 40-mesh size. The obtained particles were oven-dried at $55{ }^{\circ} \mathrm{C}$ to a constant weight. The compositional analysis (glucose, xylose, arabinose, and lignin) of the bamboo was performed according to an established National Renewable Energy Laboratory procedure [32] with a resulting composition of $49.1 \mathrm{wt} . \%$ glucose, $12.0 \mathrm{wt} . \%$ xylose, $2.0 \mathrm{wt} . \%$ arabinose, and $37.1 \mathrm{wt} . \%$ lignin.

The corncob used in this study was obtained from Shandong Province, China. Before the experiments, corncob was ground to pass through a 40-mesh screen, and then dewaxed with a 2:1 (v/v) acetone/ethanol mixture in a Soxhlet extractor $(1000 \mathrm{~mL}$, Synthware Glass Co. Ltd., Beijing, China) for $6 \mathrm{~h}$. The dewaxed corncob was oven-dried at $60^{\circ} \mathrm{C}$ to constant weight and milled for $6 \mathrm{~h}(300 \mathrm{rpm})$ with a ball-milling machine (DECO-PBM-V, Deco Co. Ltd., Hunan, China). The composition of the dewaxed corncob was $38.1 \mathrm{wt} . \%$ glucose, $31.9 \mathrm{wt} . \%$ xylose, $4.2 \mathrm{wt} . \%$ arabinose, and $25.8 \mathrm{wt} . \%$ lignin.

Chemicals $\mathrm{FeCl}_{3} \bullet 6 \mathrm{H}_{2} \mathrm{O}$ (AR, $\geq 99.0 \%$ ), $\mathrm{H}_{2} \mathrm{SO}_{4} \quad(\mathrm{AR}, \geq 98.0 \%$ ), ethanol (AR, $\geq 99.0 \%$ ), phenolphthalein ( $\mathrm{AR}, \geq 99.0 \%$ ), and $\mathrm{NaOH}(\mathrm{AR}, \geq 99.0 \%)$ were purchased from Kermel Co. Ltd. (Tianjin, China). Standard reagents, including glucose (HPLC, $\geq 99.0 \%$ ), xylose (HPLC, $\geq 99.0 \%$ ), arabinose (HPLC, $\geq 98.0 \%$ ) were purchased from Shanghai Sigma-Aldrich Trading Co. Ltd. (Shanghai, China). Deionized (DI) water was used to prepare all of the solutions. All of the chemicals were used as received.

\subsection{Methods}

\subsubsection{Catalyst Characterization}

The Fourier transform infrared (FT-IR) spectrum of the prepared bamboo-derived magnetic solid acid was recorded on a spectrophotometer (Tensor 27, Bruker Optics, Karlsruhe, Germany). An acid-base titration test was performed to verify the free hydrogen ion $\left(\mathrm{H}^{+}\right)$concentration in the bamboo-derived magnetic solid acid. In briefly, $0.1 \mathrm{~g}$ of catalyst was added into $20 \mathrm{~mL}$ of $\mathrm{NaCl}$ solution $(20 \mathrm{mmol} / \mathrm{L})$, and then stirred for $24 \mathrm{~h}(100 \mathrm{rpm})$ at room temperature. Subsequently, the mixture was filtered, and a liquid fraction $(5 \mathrm{~mL})$ was titrated with $50 \mathrm{mmol} / \mathrm{L}$ of $\mathrm{NaOH}$ solution. Phenolphthalein was used as the indicator. Experiments were done in triplicate, and the average value was obtained. The X-ray diffraction (XRD) patterns of the prepared catalysts were detected in the $2 \theta$ range of $10^{\circ}$ to $90^{\circ}$ on a Bruker D8 ADVANCE X-ray diffractometer (Karlsruhe, Germany) with $\mathrm{Cu} \mathrm{K} \alpha$ radiation. The 
thermostability of the samples was tested with thermogravimetric analysis (TA Q200, New Castle, DE, USA).

\subsubsection{Two-Step Preparation of Bamboo-Derived Magnetic Carbonaceous Solid Acid}

The hydrothermal pretreatment of bamboo was carried out in a high-pressure reactor (SLM-100, Shenlang Co. Ltd., Beijing, China). In this study, a mixture of $10 \mathrm{~g}$ of feedstock and $100 \mathrm{~mL}$ of liquid $\left(\mathrm{KOH} / \mathrm{H}_{2} \mathrm{SO}_{4}\right.$ /water) was added into the reactor. The concentrations of the $\mathrm{KOH}$ and $\mathrm{H}_{2} \mathrm{SO}_{4}$ solution were $0.25 \%, 0.5 \%, 0.75 \%, 1 \%$, and $2 \%$ respectively. A control group was performed using DI water to compare with dilute acid and alkali pretreatments. The pretreatment time, temperature, and the agitation rate were $120^{\circ} \mathrm{C}, 30 \mathrm{~min}$, and $300 \mathrm{rpm}$, respectively. Once the reaction finished, flowing water was used to cool the reactor quickly. After that, the mixture was separated by filtration. Solid residue was washed with DI water several times and dried at $60{ }^{\circ} \mathrm{C}$ overnight for the following preparation of bamboo-derived magnetic solid acid. The liquid products were determined by high-performance liquid chromatography (HPLC, Waters 2414, America) coupled with a refractive index detector (RID) and a Bio-rad Aminex HPX-87H $(300 \times 7.8 \mathrm{~mm})$ column. Five $\mathrm{mM}$ of $\mathrm{H}_{2} \mathrm{SO}_{4}$ was employed as the eluent with a flow rate of $0.5 \mathrm{~mL} / \mathrm{min}$ at $60^{\circ} \mathrm{C}$.

Five $\mathrm{g}$ of pretreated residue was dispersed in $500 \mathrm{~mL}$ of the $\mathrm{FeCl}_{3} \bullet 6 \mathrm{H}_{2} \mathrm{O}$ solution $(10 \mathrm{mmol} / \mathrm{L})$, and then stirred at room temperature $(150 \mathrm{rpm})$ for $5 \mathrm{~h}$. After impregnation, bamboo was carbonized at $500{ }^{\circ} \mathrm{C}$ for $1 \mathrm{~h}$ under nitrogen atmosphere to produce the bamboo carbon. The bamboo-derived carbon was mixed with a concentrated sulfuric acid at a ratio of $1: 10(\mathrm{~g} / \mathrm{mL})$ and sonicated for $15 \mathrm{~min}$. Subsequently, the mixture was heated under vigorous at $90^{\circ} \mathrm{C}$ for $10 \mathrm{~h}$ to introduce the sulfo-group $\left(-\mathrm{SO}_{3} \mathrm{H}\right)$ to the surface of the bamboo-derived magnetic solid precursor. After the reaction, the mixture was diluted with DI water and dried in a vacuum oven at $80^{\circ} \mathrm{C}$ for $12 \mathrm{~h}$.

\subsubsection{Hydrolysis of Corncob by Bamboo-Derived Magnetic Solid Acid}

One $\mathrm{g}$ of ball-milled corncob, $0.2 \mathrm{~g}$ of bamboo-derived magnetic solid acid, and $20 \mathrm{~mL}$ of DI water were mixed first and ultrasonicated for $30 \mathrm{~min}$, and then added into the reactor. The reaction time, temperature, and the agitation was $120^{\circ} \mathrm{C}, 30 \mathrm{~min}$, and $300 \mathrm{rpm}$, respectively. At the same time, a catalyst-free reaction including $1 \mathrm{~g}$ of ball-milled corncob and $20 \mathrm{~mL}$ of DI water was also conducted at the same reaction conditions. After the reaction, the product was filtered with a $0.22-\mu \mathrm{m}$ syringe. Liquid fractions were stored in the fridge prior to HPLC analysis, as mentioned above. Solid residues were washed with DI water several times and oven-dried at $60^{\circ} \mathrm{C}$ to a constant weight.

\subsubsection{Recyclability of Catalyst}

After reaction, the bamboo-derived magnetic solid acid catalyst was separated by a magnet. The obtained catalyst was washed with DI water and oven-dried at $70{ }^{\circ} \mathrm{C}$ for $6 \mathrm{~h}$ for the next catalytic run.

\section{Conclusions}

The conversion of corncob into reducing sugars was achieved using bamboo-derived carbonaceous magnetic solid acid as the catalyst. The prepared catalysts contained $-\mathrm{SO}_{3} \mathrm{H},-\mathrm{COOH}$, and polycyclic aromatic, and the number of $\mathrm{H}^{+}$sites was from $0.6487 \mathrm{mmol} / \mathrm{g}$ to $2.3204 \mathrm{mmol} / \mathrm{g}$. Comparing with the catalysts prepared by dilute alkali and DI water pretreatments, bamboo-derived carbonaceous magnetic solid acid prepared by dilute acid-pretreated bamboo showed better catalytic activity for the production of reducing sugars. The highest reducing sugars yield of $37.17 \%$ could be obtained using $0.25 \%$ of $\mathrm{H}_{2} \mathrm{SO}_{4}$-pretreated bamboo-derived carbonaceous solid acid as catalyst at $120^{\circ} \mathrm{C}$ for $30 \mathrm{~min}$.

Author Contributions: Formal analysis, Y.Z., J.H., and S.S.; Methodology, A.W. and H.L.; Supervision, A.W. and H.L.; Writing-review and editing, Y.Z., J.H. and H.L. 
Funding: This research was funded by National Natural Science Foundation of China (NO. 31700506), Natural Science Foundation of Guangdong Province, China (NO. 2017A030310550) and Guangdong Province Science and Technology Project (NO. 2016A010104012).

Conflicts of Interest: The authors declare no conflict of interest.

\section{References}

1. Schmitt, C.; Belén, M.; Reolon, G.; Zimmermann, M.; Raffelt, K.; Grunwaldt, J.-D.; Dahmen, N. Synthesis and regeneration of nickel-based catalysts for hydrodeoxygenation of beech wood fast pyrolysis bio-oil. Catalysts 2018, 8, 449-477. [CrossRef]

2. Xin, D.; Yang, Z.; Liu, F.; Xu, X.; Zhang, J. Comparison of aqueous ammonia and dilute acid pretreatment of bamboo fractions: Structure properties and enzymatic hydrolysis. Bioresour. Technol. 2015, 175, 529-536. [CrossRef] [PubMed]

3. Li, H.; Deng, A.; Ren, J.; Liu, C.; Lu, Q.; Zhong, L.; Peng, F.; Sun, R. Catalytic hydrothermal pretreatment of corncob into xylose and furfural via solid acid catalyst. Bioresour. Technol. 2014, 158, 313-320. [CrossRef] [PubMed]

4. Gupta, P.; Paul, S. Solid acids: Green alternatives for acid catalysis. Catal. Today 2014, 236, 153-170. [CrossRef]

5. Lee, J. Biological conversion of lignocellulosic biomass to ethanol. J. Biotechnol. 1997, 56, 1-24. [CrossRef]

6. Börjesson, M.; Larsson, A.; Westman, G.; Ström, A. Periodate oxidation of xylan-based hemicelluloses and its effect on their thermal properties. Carbohydr. Polym. 2018, 202, 280-287. [CrossRef] [PubMed]

7. Pellera, F.-M.; Gidarakos, E. Chemical pretreatment of lignocellulosic agroindustrial waste for methane production. Waste Manag. 2018, 71, 689-703. [CrossRef] [PubMed]

8. Li, H.; Ren, J.; Zhong, L.; Sun, R.; Liang, L. Production of furfural from xylose, water-insoluble hemicelluloses and water-soluble fraction of corncob via a tin-loaded montmorillonite solid acid catalyst. Bioresour. Technol. 2015, 176, 176-183. [CrossRef] [PubMed]

9. Zaccheria, F.S.F.; Iftitah, E.D.; Ravasio, N. Brønsted and Lewis Solid Acid Catalysts in the Valorization of Citronellal. Catalysts 2018, 8, 410-411. [CrossRef]

10. Solinas, A.; Taddei, M. Solid-supported reagents and catch-and-release techniques in organic synthesis. Synthesis 2007, 38, 2409-2453. [CrossRef]

11. Sebti, S.D.; Tahir, R.; Nazih, R.; Boulaajaj, S.D. Comparison of different Lewis acid supported on hydroxyapatite as new catalysts of Friedel-Crafts alkylation. Appl. Catal. A Gen. 2001, 218, 25-30. [CrossRef]

12. Tanabe, K.; Yamaguchi, T. Acid-base bifunctional catalysis by $\mathrm{ZrO}_{2}$ and its mixed oxides. Catal. Today 1994, 20, 185-197. [CrossRef]

13. Hara, M.; Yoshida, T.; Takagaki, A.; Takata, T.; Kondo, J.; Hayashi, S.; Domen, K. Carbon material as a strong protonic acid. Angew. Chem. Int. Ed. 2004, 43, 2955-2958. [CrossRef] [PubMed]

14. Oregui, M.; Miletic, N.; Hao, W.; Björnerbäck, F.; Rosnes, M.; Garitaonandia, J.; Hedin, N.; Arias, P.L.; Barth, T. High-performance magnetic activated carbon from solid waste from lignin conversion processes. Part II: Their use as NiMo catalyst supports for lignin conversion. Energy Procedia 2017, 114, 6272-6296.

15. Liu, F.; Rotaru, A.E.; Shrestha, P.M.; Malvankar, N.S.; Nevin, K.P.; Lovley, D.R. Promoting direct interspecies electron transfer with activated carbon. Energy Environ. Sci. 2012, 10, 8982-8989. [CrossRef]

16. Li, X.; Lei, T.; Wang, Z.; Li, X.; Wen, M.; Yang, M.; Chen, G.; He, X.; Xu, H.; Guan, Q.; et al. Catalytic pyrolysis of corn straw with magnetic solid acid catalyst to prepare levulinic acid by response surface methodology. Ind. Crop. Prod. 2018, 116, 73-80. [CrossRef]

17. Chen, T.; Peng, L.; Yu, X.; He, L. Magnetically recyclable cellulose-derived carbonaceous solid acid catalyzed the biofuel 5-ethoxymethylfurfural synthesis from renewable carbohydrates. Fuel 2018, 219, 344-352. [CrossRef]

18. Guo, Y.; Rockstraw, D.A. Physical and chemical properties of carbons synthesized from xylan, cellulose, and Kraft lignin by $\mathrm{H}_{3} \mathrm{PO}_{4}$ activation. Carbon 2006, 44, 1464-1475. [CrossRef]

19. Zhu, M.Q.; Wang, Z.W.; Wen, J.L.; Qiu, L.; Zhu, Y.H.; Su, Y.Q.; Wei, Q.; Sun, R.C. The effects of autohydrolysis pretreatment on the structural characteristics, adsorptive and catalytic properties of the activated carbon prepared from Eucommia ulmoides Oliver based on a biorefinery process. Bioresour. Technol. 2017, 232, 159-167. [CrossRef] [PubMed] 
20. Wei, H.; Chen, X.; Shekiro, J.; Kuhn, E.; Wang, W.; Ji, Y.; Kozliak, E.; Himmel, M.E.; Tucker, M.P. Kinetic modelling and experimental studies for the effects of $\mathrm{Fe}^{2+}$ ions on xylan hydrolysis with dilute-acid pretreatment and subsequent enzymatic hydrolysis. Catalysts 2018, 8, 39-57. [CrossRef]

21. Safari, A.; Karimi, K.; Shafiei, M. Dilute alkali pretreatment of softwood pine: A biorefinery approach. Bioresour. Technol. 2017, 234, 67-76. [CrossRef] [PubMed]

22. Xu, L.; Shi, Y.; Zhou, G.; Xu, X.; Liu, E.; Zhou, Y.; Zhang, F.; Li, C.; Fang, H.; Chen, L. Structural development and carbon dynamics of Moso bamboo forests in Zhejiang Province, China. For. Ecol. Manag. 2018, 409, 479-488. [CrossRef]

23. Sluiter, J.B.; Ruiz, R.O.; Scarlata, C.J.; Sluiter, A.D.; Templeton, D.W. Compositional analysis of lignocellulosic feedstocks: Review and description of methods. J. Agric. Food Chem. 2010, 58, 9043-9053. [CrossRef] [PubMed]

24. Qi, X.; Watanabe, M.; Aida, T.M.; Smith, R.L., Jr. Sulfated zirconia as a solid acid catalyst for the dehydration of fructose to 5-hydroxymethylfurfural. Catal. Commun. 2009, 10, 1771-1775. [CrossRef]

25. Li, H.; Deng, A.; Ren, J.; Liu, C.; Wang, W.; Peng, F.; Sun, R. A modified biphasic system for the dehydration of d-xylose into furfural using $\mathrm{SO}_{4}{ }^{2-} / \mathrm{TiO}^{2-} \mathrm{ZrO}_{2} / \mathrm{La}^{3+}$ as a solid catalyst. Catal. Today 2014, 234, $251-256$. [CrossRef]

26. Hu, L.; Tang, X.; Wu, Z.; Lin, L.; Xu, J.; Xu, N.; Dai, B. Magnetic lignin-derived carbonaceous catalyst for the dehydration of fructose into 5-hydroxymethylfurfural in dimethylsulfoxide. Chem. Eng. J. 2015, 263, $299-308$. [CrossRef]

27. Jia, X.; Dai, R.; Sun, Y.; Song, H.; Wu, X. One-step hydrothermal synthesis of $\mathrm{Fe}_{3} \mathrm{O}_{4} / \mathrm{g}-\mathrm{C}_{3} \mathrm{~N}_{4}$ nanocomposites with improved photocatalytic activities. J. Mater. Sci. 2016, 27, 3791-3798. [CrossRef]

28. Ishii, T.; Hiroi, T.; Thomas, J.R. Feruloylated xyloglucan and p-coumaroyl arabinoxylan oligosaccharides from bamboo shoot cell-walls. Phytochemistry 1990, 29, 1999-2003. [CrossRef]

29. Xu, F.; Yu, J.; Tesso, T.; Dowell, F.; Wang, D. Qualitative and quantitative analysis of lignocellulosic biomass using infrared techniques: A mini-review. Appl. Energ. 2013, 104, 801-809. [CrossRef]

30. Faix, O. Classification of lignins from different botanical origins by FT-IR Spectroscopy. Holzforschung 1991, 45, 21-28. [CrossRef]

31. Li, J.; Li, K.; Zhang, T.; Wang, S.; Jiang, Y.; Bao, Y.; Tie, M. Development of activated carbon from windmill palm sheath fiber by $\mathrm{KOH}$ activation. Fiber. Polym. 2016, 17, 880-887. [CrossRef]

32. He, C.; Sasaki, T.; Shimizu, Y.; Koshizaki, N. Synthesis of ZnO nanoparticles using nanosecond pulsed laser ablation in aqueous media and their self-assembly towards spindle-like ZnO aggregates. Appl. Surf. Sci. 2008, 254, 2196-2202. [CrossRef]

(C) 2019 by the authors. Licensee MDPI, Basel, Switzerland. This article is an open access article distributed under the terms and conditions of the Creative Commons Attribution (CC BY) license (http:/ / creativecommons.org/licenses/by/4.0/). 